\title{
Decline in wintertime air-mass transition frequencies in the USA
}

\author{
David M. Hondula*, Robert E. Davis \\ Department of Environmental Sciences, PO Box 400123, University of Virginia, Charlottesville, Virginia 22904, USA
}

\begin{abstract}
Air-mass transitions are an important component of atmospheric circulation, but are difficult to objectively identify and analyze in the context of decadal-scale climate change. Spatial synoptic classification (SSC) uses surface weather observations of daily dew point temperature range, sea-level pressure range, and wind shift to identify days with a distinct change from one air mass to another ('transition days'). Thus, the SSC offers a unique opportunity to examine the climatology of synoptic-scale transition events. The frequency of the transition type has significantly declined across United States over the second half of the twentieth century, potentially revealing a climatic shift toward fewer abrupt air-mass changes, but the underlying causes have not been well-documented to date. We link the decline in winter transition frequency to decreasing intra-daily moisture and pressure variability by examining the largest within-day dew point temperature and sea-level pressure changes. Fewer transitions are being observed in the continental United States because of increasing daily minimum dew point temperatures in the upper Midwest and smaller pressure changes over $24 \mathrm{~h}$ periods in the western states. The frequency and intensity of air-mass transitions are closely tied to other components of the climate system; therefore, examination of transition trends serves as a novel framework for exploring climatic change.
\end{abstract}

KEY WORDS: Spatial synoptic classification - Climate variability · Climate change $\cdot$ Frontal climatology $\cdot$ Air mass $\cdot$ Circumpolar vortex

\section{INTRODUCTION}

\subsection{Spatial synoptic classification and trends in transition day frequencies}

An increasing body of research is focusing on the nature and causes of changes in climate variability, rather than on mean conditions. Most of the focus has been on variability related to extremes (e.g. heat waves: Meehl \& Tebaldi 2004; drought: Rind et al. 1990; heavy precipitation: Karl \& Knight 1998), but it is also possible that climate change can be evaluated via more regularly observed patterns in the weather. Much of the middleand high-latitude precipitation is found along boundaries between air masses, for example, and a long-term trend in the frequency, intensity, or magnitude of these boundaries would impact hydrological processes and human and natural systems.
Air-mass and weather-type identification systems offer a useful rubric to consider climate and weather by accounting for multiple variables simultaneously. The spatial synoptic classification (SSC) (Kalkstein et al. 1998, Sheridan 2002) is one such system that uses 4-times daily surface observations of temperature, dew point temperature, sea-level pressure, wind speed, wind direction, and cloud cover to classify days into 1 of 6 air-mass types or a transition category. The 6 airmass types reflect varying thermal/moisture characteristics (e.g. 'dry polar' and 'moist tropical') analogous to the classic Bergeron scheme, while the transition type is intended to capture days in which one air mass is replaced by another. Although the greatest benefits of such an approach are probably in examining relationships between the atmosphere and surface environment, these systems can also be applied to climate change. Using the SSC, Knight et al. (2008) identified 
increasing frequencies of warm, moist air masses and decreasing frequencies of cool dry air masses across the United States over approximately the past 5 decades. Their analysis also reported a statistically significant decline in transition frequencies evident across much of the United States, particularly in winter. Such findings cannot point directly to a particular cause of climatic changes (such as a change in the atmospheric circulation), but they do present a more comprehensive summary than one might obtain from examining trends in the means of individual variables.

The decline in transition frequency is among the most notable results of the SSC trend analyses published to date; however, the underlying cause of the decline has yet to be examined. In very general terms, days with large changes in dew point temperature, sea-level pressure, and wind are identified as transition days in the SSC. A decline in the variability of one or more of these 'transition indicator' variables should lead to decreasing transition frequency. The observed trend toward fewer transitions could arise from an actual decrease in the number of transition events, but it could also arise from weaker transitions (that fall below SSC detection thresholds), increased persistence (longer residence time) of air masses, transitions with a smaller spatial extent, or transitions that occur more slowly. A result suggesting temporal trends in any of these factors could provide a new perspective on the synoptic-scale components of climate change over the past several decades.

\subsection{Potential climatic influences}

Most of the recent literature related to temporal trends in daily weather variability has focused on surface temperature and precipitation. Twenty-four hour temperature variability for the United States has decreased over the period 1911-1992 and for several other Northern Hemisphere regions over different time periods (Karl et al. 1995). In China, a decrease in wintertime daily temperature variability over the period 1954-2000 has been linked to a decreasing frequency of low temperature extremes (Gong \& Ho 2004). Further, extreme single-day precipitation events are increasingly contributing to total precipitation amounts (Karl et al. 1995).

In this research, we analyze dew point temperature, sea-level pressure, and wind speed variability using the daily range (difference between maximum and minimum within a $24 \mathrm{~h}$ period). As noted by Karl et al. (1995), there are many different methods to measure variability, and the method chosen directly impacts the results and conclusions drawn. Here we select the daily range because it is the variable used by the SSC to identify transition days. Trends in both dew point temperature and pressure variability should be closely tied with shifts in the hemispheric circulation (e.g. Burnett 1993, Frauenfeld \& Davis 2003).

Throughout the year, the position, strength, and shape of the jet stream(s) over North America determine much of the synoptic-scale climate variability. Jet stream position is coupled to the air-mass climatology of individual stations, as those to the north of the polar front jet have greater exposure to polar air masses, and those to the south, tropical. The strongest feature of the jet stream in both hemispheres is located along the equatorward boundary of a polar vortex, the region in the upper atmosphere of the maximum meridional geopotential height gradient (Frauenfeld \& Davis 2003). A contracting winter polar vortex has been observed in recent decades (Burnett 1993, Davis \& Benkovic 1994, Frauenfeld \& Davis 2003), although some research suggests no temporal trend (Rohli et al. 2005). Jet stream probabilities (the likelihood of the jet stream being observed over a given area) have been increasing over Canada, consistent with a contracting vortex (Strong \& Davis 2007). For the region of interest in the present study, troughing has increased over the eastern Pacific, ridging has increased over western North America, and little to no trend has been observed over eastern North America (Frauenfeld \& Davis 2003). Increased meridionality in the long-wave mid-latitude circulation pattern suggests a slower propagation of systems across the continent, and a general northward shift in the vortex suggests a displacement of storm tracks to the north-both factors that would likely decrease United States transition frequencies.

Transition frequency patterns should also be associated with trends in cyclone and anticyclone activity. As no single best measure of such activity exists, research on this topic often employs different methods. However, for the Northern Hemisphere many studies point to a common pattern: decreases in cyclone activity in the mid-latitudes $\left(30^{\circ} \mathrm{N}\right.$ to $\left.60^{\circ} \mathrm{N}\right)$ and a corresponding increase in the high latitudes $\left(60^{\circ} \mathrm{N}\right.$ to $\left.90^{\circ} \mathrm{N}\right)$ over the past several decades (Changnon et al. 1995, McCabe et al. 2001, Paciorek et al. 2002). Collectively, these results may indicate changes in the speed and/or meridionality of hemispheric flow, but certainly suggest decreasing transition frequencies, as fewer cyclones likely would result in fewer boundaries between air masses differing in dew point temperature, sealevel pressure, and wind. The observed decreases in temperature variability and cyclone activity are consistent with model projections of a warming climate in which: (1) reduction in the latitudinal temperature gradient requires fewer cyclones to transport energy between the equator and poles (Held 1993, Yin 2005), 
(2) increased moisture in the atmosphere causes the cyclones that do exist to become more 'efficient' transporters of energy and, thus, more intense (Lambert 1995, Carnell \& Senrio 1998), and (3) feedback mechanisms related to snow and ice cover enhance warming trends at high latitudes (Trenberth et al. 2007).

\subsection{Research overview}

We examined the linkages between transition frequency and short-term variability of dew point temperature, sea-level pressure, and wind (the variables used by the SSC to identify transition days) for winter months in the contiguous United States from 1950-2007 to place the declining transition frequencies in the context of larger scale climate change. The observed declines in transition frequencies are linked to changes in transition indicator variables and are related to largescale upper atmospheric circulation changes over the continental United States.

\section{SSC TRANSITION IDENTIFICATION}

Daily SSC calendars and corresponding $6 \mathrm{~h}$ meteorological data are utilized for a spatial network of 63 firstorder weather stations across the contiguous United States over the period December 1950-February 2007 (Table 1, Fig. 1). We chose this particular sample of stations to create an evenly spaced network across the entire spatial domain, with consistent periods of record and minimal missing cases. The stations chosen are those that have the most data available for the entire period of record and fill the entire spatial domain at the synoptic scale. We limit the analysis to winter, defined as December, January, and February (DJF), the season when transition frequencies are highest and frequency declines are greatest (Sheridan 2002, Knight et al. 2008). The meteorological parameters employed by the SSC are 4-times daily $(04: 00,10: 00,16: 00$, and 22:00 h eastern standard time [EST]) surface air temperature $\left({ }^{\circ} \mathrm{C}\right)$, dew point temperature $\left({ }^{\circ} \mathrm{C}\right)$, sea-level pressure (hPa), $u$ - (west-east) and $v$ - (south-north) components of the horizontal wind vector $\left(\mathrm{m} \mathrm{s}^{-1}\right)$, cloud cover (tenths of sky covered), diurnal temperature range $\left({ }^{\circ} \mathrm{C}\right)$, diurnal dew point temperature range $\left({ }^{\circ} \mathrm{C}\right.$, henceforth written as $R_{\mathrm{Td}}$ ), diurnal sea-level pressure range (mb, henceforth $R_{\mathrm{P}}$ ), and diurnal wind shift ( $\mathrm{m} \mathrm{s}^{-1}$, henceforth $R_{\mathrm{W}}$ ). The range is defined as the absolute value of the difference between the maximum and minimum of the 4-times daily observations, or, in the case of wind, the magnitude of the largest vector difference between 2 of the 4-times daily wind vectors.

The SSC is considered a hybrid classification scheme as it incorporates both subjective and automated components. The procedure relies on a user's identification of 'seed days' in the weather record of each station. A 'seed day' is one that exemplifies the typical characteristics of a particular air mass (or a transition day) at a given location and time of year. Through the identification of seed days, a daily calendar is developed with the expected mean weather characteristics for each of the 7 types. This calendar contains the theoretical or expected daily weather observations that would be observed with each air-mass type throughout the year.
Fig. 1. Network of firstorder weather stations used in analysis. See Table 1 for full station names

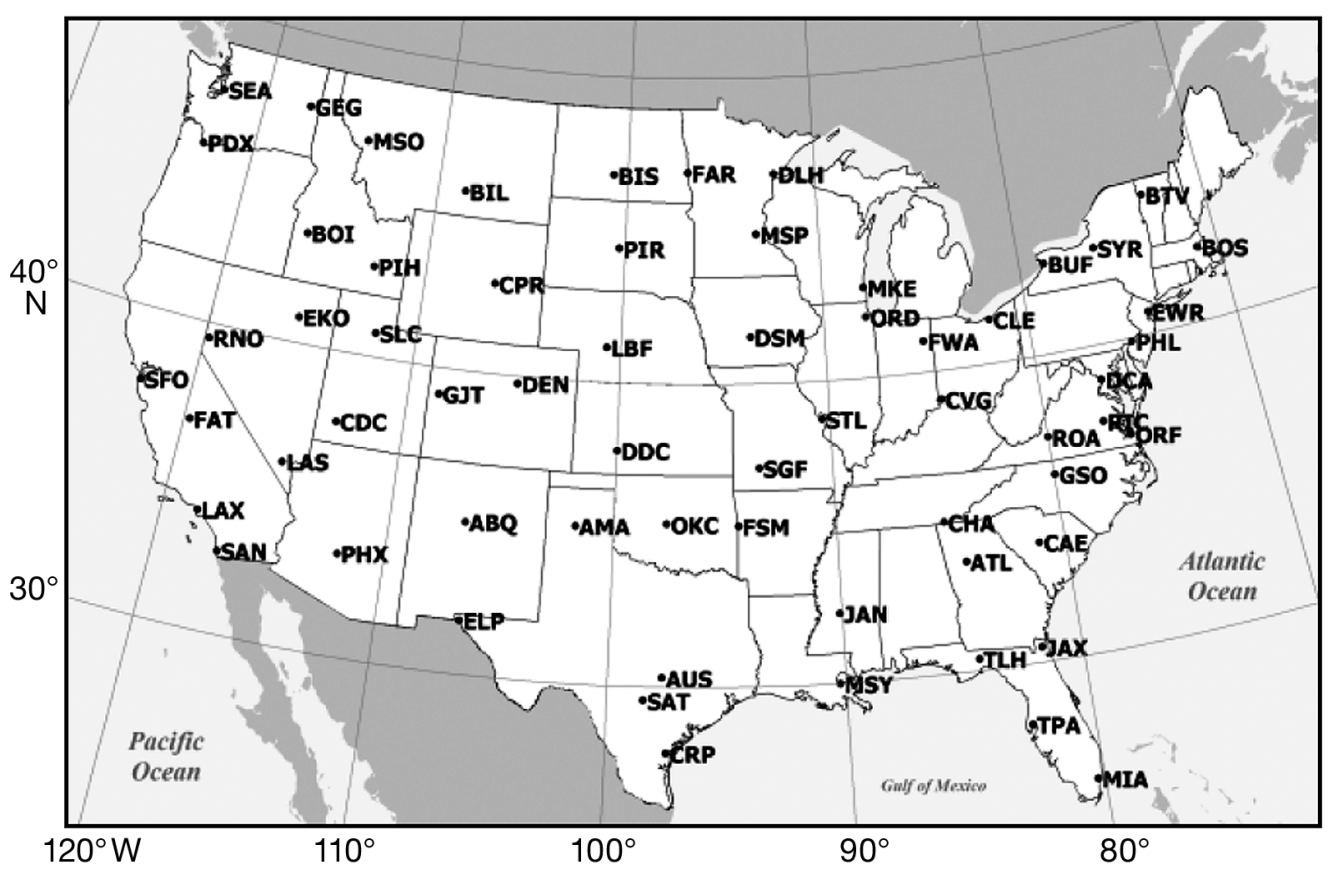


Table 1. List of first-order weather stations used in analysis with 3-letter identification codes and station location

\begin{tabular}{|c|c|c|c|c|}
\hline Station & ID & \multicolumn{2}{|c|}{$\begin{array}{l}\text { Coordinates } \\
\left({ }^{\circ} \mathrm{N}\right) \quad\left({ }^{\circ} \mathrm{W}\right)\end{array}$} & $\begin{array}{l}\text { Completeness }(\%) \\
\text { [dropped years] }\end{array}$ \\
\hline Albuquerque, NM & $\mathrm{ABQ}$ & 35.05 & 106.60 & 93.9 \\
\hline Amarillo, TX & AMA & 35.23 & 101.70 & 94.4 \\
\hline Atlanta, GA & ATL & 33.65 & 84.42 & 94.9 \\
\hline Austin, TX & AUS & 30.30 & 97.70 & 94.8 \\
\hline Billings, MT & BIL & 45.80 & 108.53 & 94.2 \\
\hline Bismarck, ND & BIS & 46.77 & 100.75 & $93.1[2007]$ \\
\hline Boise, ID & BOI & 43.57 & 116.22 & $94.0[1957]$ \\
\hline Boston, MA & BOS & 42.37 & 71.03 & 94.1 \\
\hline Burlington, VT & BTV & 44.47 & 73.15 & 93.6 \\
\hline Buffalo, NY & BUF & 42.93 & 78.73 & 94.3 \\
\hline Columbia, SC & $\mathrm{CAE}$ & 33.95 & 81.12 & $94.4[1974]$ \\
\hline Cedar City, UT & $\mathrm{CDC}$ & 37.70 & 113.10 & 93.9 \\
\hline Chattanooga, TN & $\mathrm{CHA}$ & 35.03 & 85.20 & 94.8 \\
\hline Cleveland, OH & CLE & 41.42 & 81.87 & 94.3 \\
\hline Casper, WY & $\mathrm{CPR}$ & 42.92 & 106.47 & 94.2 \\
\hline Corpus Christi, TX & CRP & 27.77 & 97.50 & 94.8 \\
\hline Covington, KY & CVG & 39.05 & 84.67 & 94.6 \\
\hline Washington-National, DC & DCA & 38.85 & 77.04 & 94.6 \\
\hline Dodge City, KS & $\mathrm{DDC}$ & 37.77 & 99.97 & 94.1 \\
\hline Denver, CO & DEN & 39.75 & 104.87 & 94.1 \\
\hline Duluth, MN & $\mathrm{DLH}$ & 46.83 & 92.18 & 93.8 \\
\hline Des Moines, IA & DSM & 41.53 & 93.65 & 94.2 \\
\hline Elko, NV & EKO & 40.83 & 115.78 & $\begin{array}{c}83.2[1965,1993-1994 \\
1997-2001]\end{array}$ \\
\hline El Paso, TX & ELP & 31.80 & 106.40 & 94.2 \\
\hline Newark, NJ & EWR & 40.70 & 74.17 & 94.5 \\
\hline Fargo, ND & FAR & 46.90 & 96.80 & $92.9[2007]$ \\
\hline Fresno, CA & FAT & 36.77 & 119.72 & 94.7 \\
\hline Ft. Smith, AR & FSM & 35.33 & 94.37 & 94.6 \\
\hline Ft. Wayne, IN & FWA & 41.00 & 85.20 & 94.4 \\
\hline Spokane, WA & GEG & 47.63 & 117.53 & 94.3 \\
\hline Grand Junction, CO & GJT & 39.12 & 108.53 & $92.9[1955]$ \\
\hline Greensboro, NC & GSO & 36.08 & 79.95 & 94.3 \\
\hline Jackson, MS & JAN & 32.32 & 90.08 & 94.6 \\
\hline Jacksonville, FL & JAX & 30.50 & 81.70 & 94.9 \\
\hline Las Vegas, NV & LAS & 36.08 & 115.17 & 94.8 \\
\hline Los Angeles, CA & LAX & 33.93 & 118.40 & 94.9 \\
\hline North Platte, NE & LBF & 41.13 & 100.68 & 93.9 \\
\hline Miami, FL & MIA & 25.82 & 80.28 & 94.6 \\
\hline Milwaukee, WI & MKE & 42.95 & 87.90 & 94.2 \\
\hline Missoula, MT & MSO & 46.92 & 114.08 & 94.7 \\
\hline Minneapolis-St. Paul, MN & MSP & 44.88 & 93.22 & 94.4 \\
\hline New Orleans, LA & MSY & 29.98 & 90.25 & 94.9 \\
\hline Oklahoma City, OK & OKC & 35.40 & 97.60 & 94.5 \\
\hline Chicago, IL & ORD & 41.98 & 87.90 & 94.5 \\
\hline Norfolk, VA & ORF & 36.90 & 76.20 & 94.6 \\
\hline Portland, OR & PDX & 45.60 & 122.60 & 94.9 \\
\hline Philadelphia, PA & PHL & 39.88 & 75.25 & 94.4 \\
\hline Phoenix, AZ & PHX & 33.43 & 112.02 & 94.8 \\
\hline Pocatello, ID & $\mathrm{PIH}$ & 42.92 & 112.60 & 94.3 \\
\hline Pierre, SD & PIR & 44.38 & 100.28 & 93.8 \\
\hline Richmond, VA & RIC & 37.50 & 77.33 & 94.6 \\
\hline Reno, NV & RNO & 39.50 & 119.78 & 94.7 \\
\hline Roanoke, VA & ROA & 37.32 & 79.97 & 94.3 \\
\hline San Diego, CA & SAN & 32.73 & 117.17 & 94.9 \\
\hline San Antonio, TX & SAT & 29.53 & 98.47 & 94.4 \\
\hline Seattle-Tacoma, WA & SEA & 47.45 & 122.30 & 94.8 \\
\hline San Francisco, CA & $\mathrm{SFO}$ & 37.62 & 122.38 & 94.9 \\
\hline Springfield, MO & SGF & 37.23 & 93.38 & $93.2[1964]$ \\
\hline Salt Lake City, UT & SLC & 40.78 & 111.97 & 94.8 \\
\hline St. Louis, MO & STL & 38.75 & 90.37 & 94.5 \\
\hline Syracuse, NY & SYR & 43.12 & 76.12 & 94.3 \\
\hline Tallahassee, FL & TLH & 30.38 & 84.37 & 95.0 \\
\hline Tampa, FL & TPA & 27.97 & 82.53 & 94.5 \\
\hline
\end{tabular}

To classify each actual day in station records, a squared $z$-score is calculated for each variable of each air mass on a daily basis as the square of the difference between the actual and theoretical values squared divided by the standard deviation. These scores are summed across all 12 variables, and the air mass with the lowest sum is selected as that day's SSC classification. After this primary classification, a secondary method determines whether the within-day variation is sufficiently large such that the day should be identified as a 'transition.' The scoring procedure is repeated as above, except here only the 3 transition variables are evaluated. If the new transition $z$-score sum for the transition type is lower than the transition $z$-score sum for the airmass type designated from the primary classification, the day is re-classified as transition. If it is greater, the day retains its original air-mass classification. There is no absolute minimum criterion that needs to be met for transition classification in terms of diurnal range; rather, the diurnal range must be more similar to that expected for transition days than that expected for any of the 6 air-mass types. This procedure is repeated for every day throughout the record to generate an SSC calendar for each station. Complete details on the SSC procedure may be found in Sheridan (2002), and transition classification probabilities are listed for the entire record at every station on the SSC web page (http://sheridan.geog. kent.edu/ssc.html).

The SSC procedure to identify transition days only uses $R_{\mathrm{Td}}, R_{\mathrm{P}}$, and $R_{\mathrm{W}}$, and these variables are thus emphasized in this research (referred to, henceforth, as the 'transition indicator variables'). Because the SSC is a discrete daily classification that only utilizes observations taken within a $24 \mathrm{~h}$ time window, measurements of within-day changes of variables are limited to $18 \mathrm{~h}$ intervals (rather than $24 \mathrm{~h}$ ). It is possible, though, that shifts in overnight transitions that are missed by the SSC could bias the observed trends. We analyze trends in each of the transition indicator vari- 
ables (at the threshold percentile determined above) for the four $6 \mathrm{~h}$ time steps (4:00-10:00, 10:00-16:00, 16:00-22:00, 22:00-4:00 h on the next day), with a null hypothesis of no difference between the trends in each time step within each variable (i.e. the 4:00-10:00 h $R_{\mathrm{Td}}$ and 10:00-16:00 h $R_{\mathrm{Td}}$ have similar trends). To accommodate the multiple comparisons between the overnight range trends and the other time steps and maintain an effectively similar chance of making a Type I error, we reduce $\alpha$ for this specific test to 0.01 .

\section{METHODS}

Linear regression is used to establish the transition frequency trends over the entire period of record at each station. In the event that $>30 \mathrm{~d}$ are missing from the SSC record in a given year, that year is excluded from the analysis. The SSC calendars and corresponding meteorological records are very complete, with an average of $94.1 \%$ data completeness across all stations (see Table 1). At only 7 stations were any years removed from analysis, and, among 6 of those, no more than 1 yr was removed. Because of the relatively small sample size (57 yr), we apply a bootstrapping technique that resamples the data 1000 times. The general principle of bootstrapping is to generate a distribution of estimates for a statistical parameter of interest. The distribution provides a quantitative measure of the robustness of a particular estimate. The parameter of interest in this research is the estimated linear regression slope $b$. In each resampling iteration, 57 pairs of the independent (year) and dependent (transition frequency) variables are drawn with replacement. A simple least-squares linear regression slope is calculated for each of these randomly generated sets of 57 pairs. The observed trend in the original data is considered statistically significant if the 2.5th and 97.5th percentile regression slopes from the bootstrap trials have the same sign. (The method is adapted from Efron \& Tibshirani 1986, and applied to all regression models in this research, except in the use of stepwise multiple linear regression.)

Generally speaking, the number of transition days identified at a given station each winter depends on how many days there are with a sufficiently large intra-day change in $R_{\mathrm{Td}}, R_{\mathrm{P}}$, and/or $R_{\mathrm{W}}$. To properly compare transition day frequency to the year-to-year variability in the underlying indicator variables, we need to quantify the threshold values that lead to days being identified as transition days rather than air-mass days. One specific threshold for each variable does not exist because the classification scheme uses all 3 simultaneously, which means that it is possible that a day has a large change in dew point temperature, but may not be classified as a transition or vice versa. However, we would expect a general progression toward a greater likelihood of transition days in years when high values of $R_{\mathrm{Td}}, R_{\mathrm{P}}$, and $R_{\mathrm{W}}$ were more commonly observed.

To determine more specifically which value we need to examine on a year-to-year basis, at each station, we group all winter days into deciles of the 3 transition indicator variables (10 equally sized bins). We then examine the frequency of transition days (out of all days) that fall within each decile. If we observed that $75 \%$ of days were transitions when $R_{\mathrm{Td}}$ was above the 90th percentile from the climatological record, but only $25 \%$ were transitions when it was between the 80th and 90th percentiles, we would be inclined to use the 90th percentile as our most useful measure of $R_{\mathrm{Td}}$. Although we know a priori that the frequency of transition days will increase from the lowest decile to the highest, it is not known whether there is a linear increase, a sharp increase at the high deciles, or some other pattern. We acknowledge that the identification of an appropriate 'threshold' percentile for the transition indicator variables is subjective, but this strategy enables us to identify an appropriate indicator of the year-to-year changes in the within-day range.

We determine the relative impact of each transition indicator variable on transition frequency on a stationby-station basis using forward stepwise multiple linear regression. Although there may be trends in all 3 range variables at a particular station, it is possible that one variable accounts for a large portion of the transition frequency trend. Conversely, the decline in all 3 may be collectively reducing the number of transition days classified. The regression is run using a MATLAB algorithm that optimizes root mean squared error (RMSE) for the entire model. Variables are added with a partial-p (probability value of the partial- $F$ statistic for each variable) of 0.05 or less and are removed if partial-p exceeds 0.10 . We acknowledge that, in an ideal setting, the stepwise regression might exclude a variable that provides only a minor improvement in RMSE; however, to reduce subjectivity, we allow the algorithm to add all variables that meet the partial-p criterion.

To illustrate, scatter-plots of transition frequencies and the 90th percentiles of each of the 3 transition indicator variables are shown for Duluth, MN (DLH) in Fig. 2. Of the 3 variables, the 90th percentile of $R_{\mathrm{Td}}$ is most highly correlated to transition frequency, and the 90th percentile $R_{\mathrm{P}}$ is also positively related. The 90th percentile $R_{\mathrm{W}}$ does not demonstrate a strong relationship with transition frequency, and, at DLH, $R_{\mathrm{W}}$ is not included as a predictor in the stepwise regression.

Following this analysis, we then attempt to link trends in the change variables to trends in the under- 

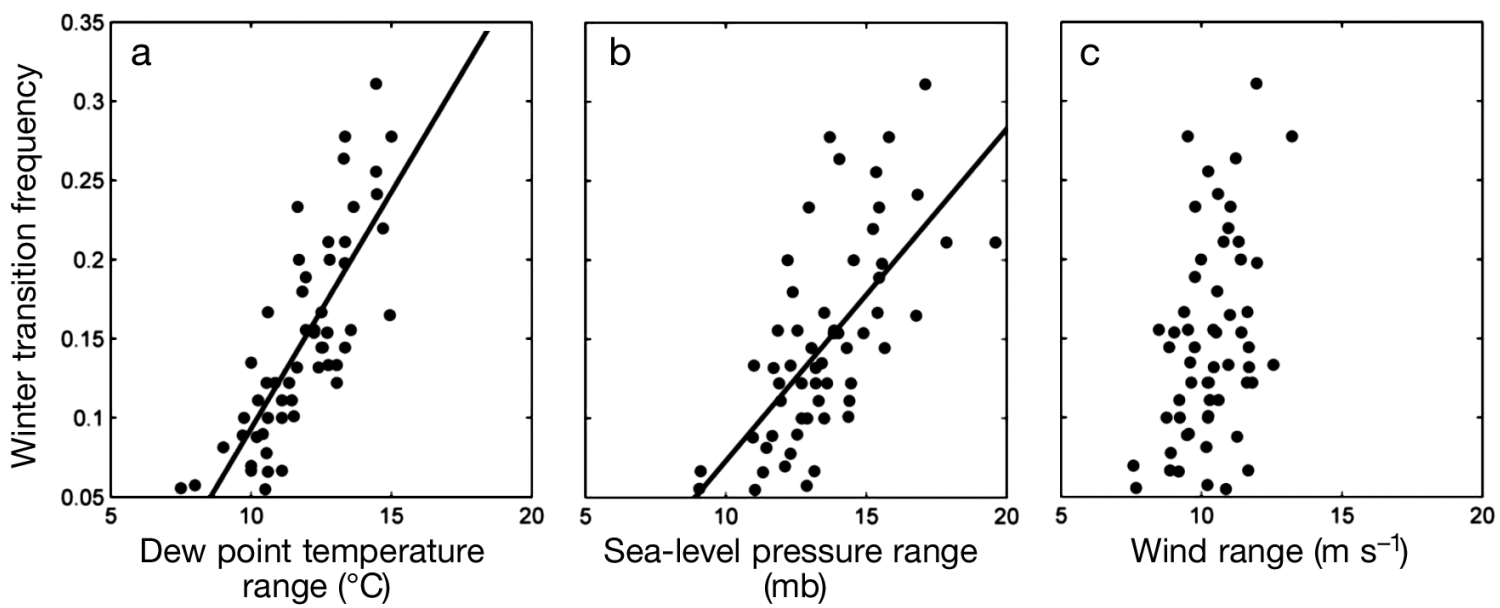

Fig. 2. Scatter-plots of winter (DJF) transition frequencies at Duluth, Minnesota, 1951-2007 and (a) 90th percentile dew point temperature range, (b) 90th percentile sea-level pressure range, and (c) 90th percentile wind range. In a stepwise multiple linear regression, the first 2 variables are included as statistically significant predictors of transition frequency (regression slope indicated by solid line), whereas the third is not

lying raw data. For example, our results might connect decreases in the upper percentiles of $R_{\mathrm{Td}}$ to increasing minimum dew point temperatures.

We next consider the underlying causes of trends in the transition indicator variables themselves using simple linear regression (with the bootstrapping procedure described above). A trend in the seasonal diurnal range of any variable can occur for 1 of 3 reasons: a change in the minimum values, a change in the maximum values, or a longer duration between minima and maxima. After determining the appropriate percentile of $R_{\mathrm{Td}}, R_{\mathrm{P}}$, and $R_{\mathrm{W}}$ to measure each winter, we then compare these trends to the raw observations (observed dew point temperature, sea-level pressure, and wind) to see which of the 3 possibilities listed above might be occurring.

Although at this point we will have numerically tied climatic trends to the transition frequency trends, we also aim to place the trends in transition frequency and daily weather variability in the context of the larger scale circulation. To do so we utilize the monthly Northern Hemisphere circumpolar vortex data from Frauenfeld \& Davis (2003). The vortex data are intended to represent the region of strongest westerly flow and are generated from NCEP/NCAR reanalysis geopotential height fields by tracking the north-south shifts of the region of maximum meridional height gradient along longitudinal transects. A mean monthly northern, center, and southern vortex position is calculated for 3 constant pressure levels of the atmosphere at $5^{\circ}$-spaced meridians; we consider the position of their center $500 \mathrm{hPa}$ height contours over the domain $60^{\circ} \mathrm{W}-150^{\circ} \mathrm{W}$, which includes the entire conterminous United States and extends into the eastern Pacific. The vortex data are available from winter 1950-1951 through 2001-2002. At each station, we generate 18 different sets of bootstrapped simple linear regression models relating transition frequency to the winter average vortex position in each $5^{\circ}$ band over the domain.

\section{RESULTS}

\subsection{Climatology of transition days}

Winter transition frequencies vary from 5 to $15 \%$ across the United States on average, with the greatest number of transitions observed in the north and east, and the fewest in the southern Plains and Southwest (Fig. 3). The regions of maximum transition frequencies correspond with preferred tracks for anticyclones (upper Midwest) and cyclones (east coast) over North America (Klein 1957). Decreasing winter transition frequencies are observed at 37 of the 63 stations, and increasing winter transition frequencies are not observed (Fig. 4). On average, the transition frequency at stations with a significant trend decreases by $0.88 \%$ decade $^{-1}$ (note: a $1 \%$ decade $^{-1}$ trend refers to the change in frequency of transition days compared to all days, i.e. a frequency decline from 15 to $14 \%$ rather than 15 to $14.85 \%$ ). We observe 2 areas of maximum decline: one in the upper Midwest and the other in the northern Rockies. In these regions, the rates of decrease approach $2 \%$ decade $^{-1}$. At Boise, Idaho, for example, the winter transition frequency decreased from approximately $15 \%$ in the late 1950 s to $6-8 \%$ in most recent years. The trends are generally consistent over the period of record, with a few stations showing a greater rate of decline during the 1960s than in later decades. 


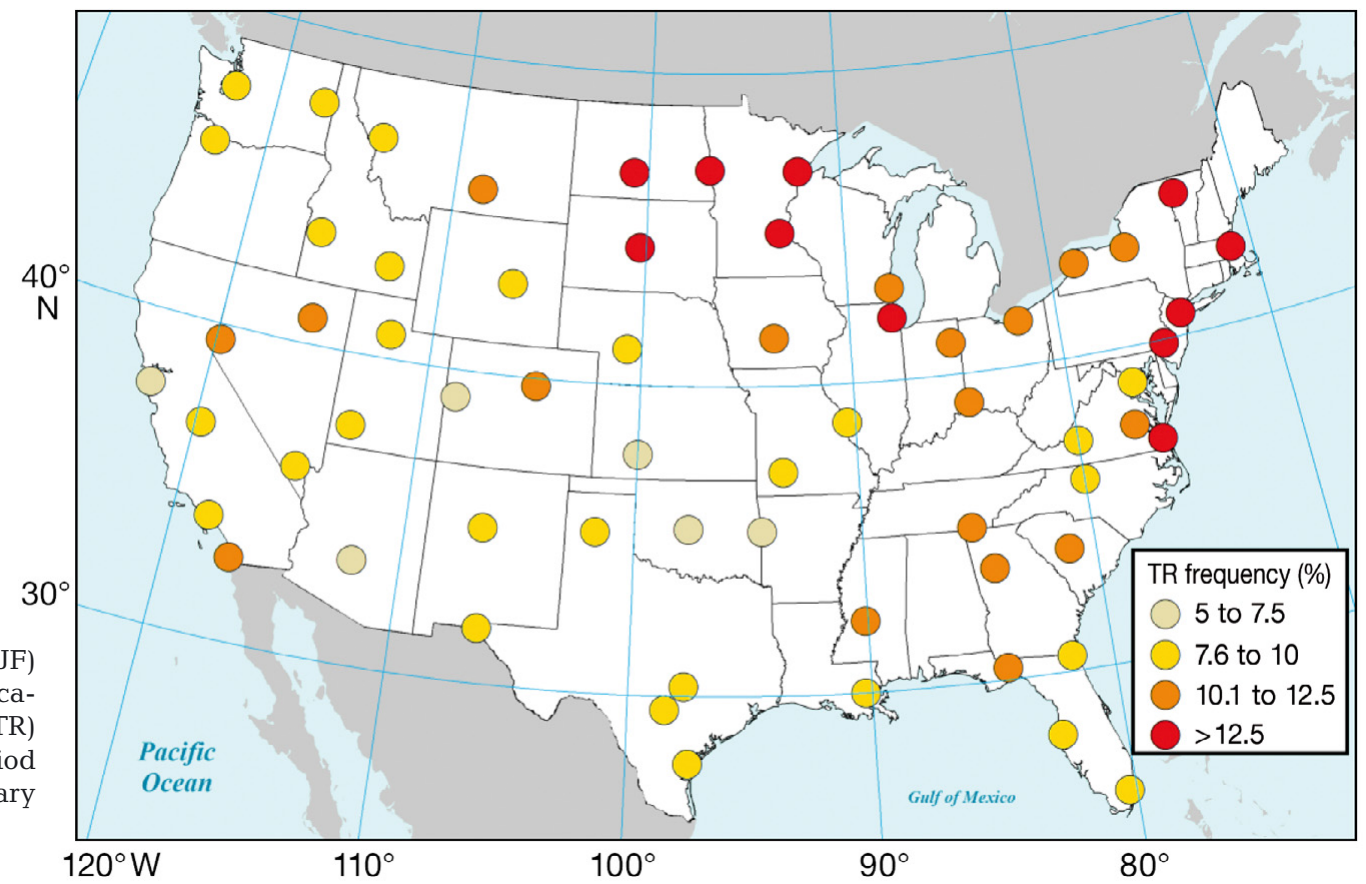

Fig. 3. Mean winter (DJF) spatial synoptic classification transition type (TR) frequency for the period December 1950-February 2007

$$
120^{\circ} \mathrm{W}
$$

$110^{\circ}$

are rarely observed among the lowest 8 deciles for all 3 variables (Fig. 5). When $R_{\mathrm{Td}}, R_{\mathrm{P}}$, or $R_{\mathrm{W}}$ falls in the ninth decile, transition frequencies begin to increase to $15-25 \%$ at most stations. Transition days are very rare when $R_{\mathrm{Td}}, R_{\mathrm{P}}$, or $R_{\mathrm{W}}$ fall below the 80th percentile. Finally, in the uppermost decile, transition frequencies approach $50 \%$ or greater at many stations. Only at the 90th percentile do we begin to see a break between the subset of days that are mostly non-transitional to the sub-

A critical goal is to determine an optimal way to utilize the transition indicator variables in analysis to connect climatic trends to the decline in transition frequencies. By sorting the relative frequency of transition days at each station into the deciles of each transition indicator variable $\left(R_{\mathrm{Td}}, R_{\mathrm{P}}, R_{\mathrm{W}}\right)$, we observe that transition days
Fig. 4. Bootstrapped linear regression trends in winter (DJF) spatial synoptic classification transition (TR) type fre- $30^{\circ}$ quency for the period December 1950-February 2007. Stations with a southward-pointing triangle exhibit significantly decreasing frequencies; grey dots indicate no trend

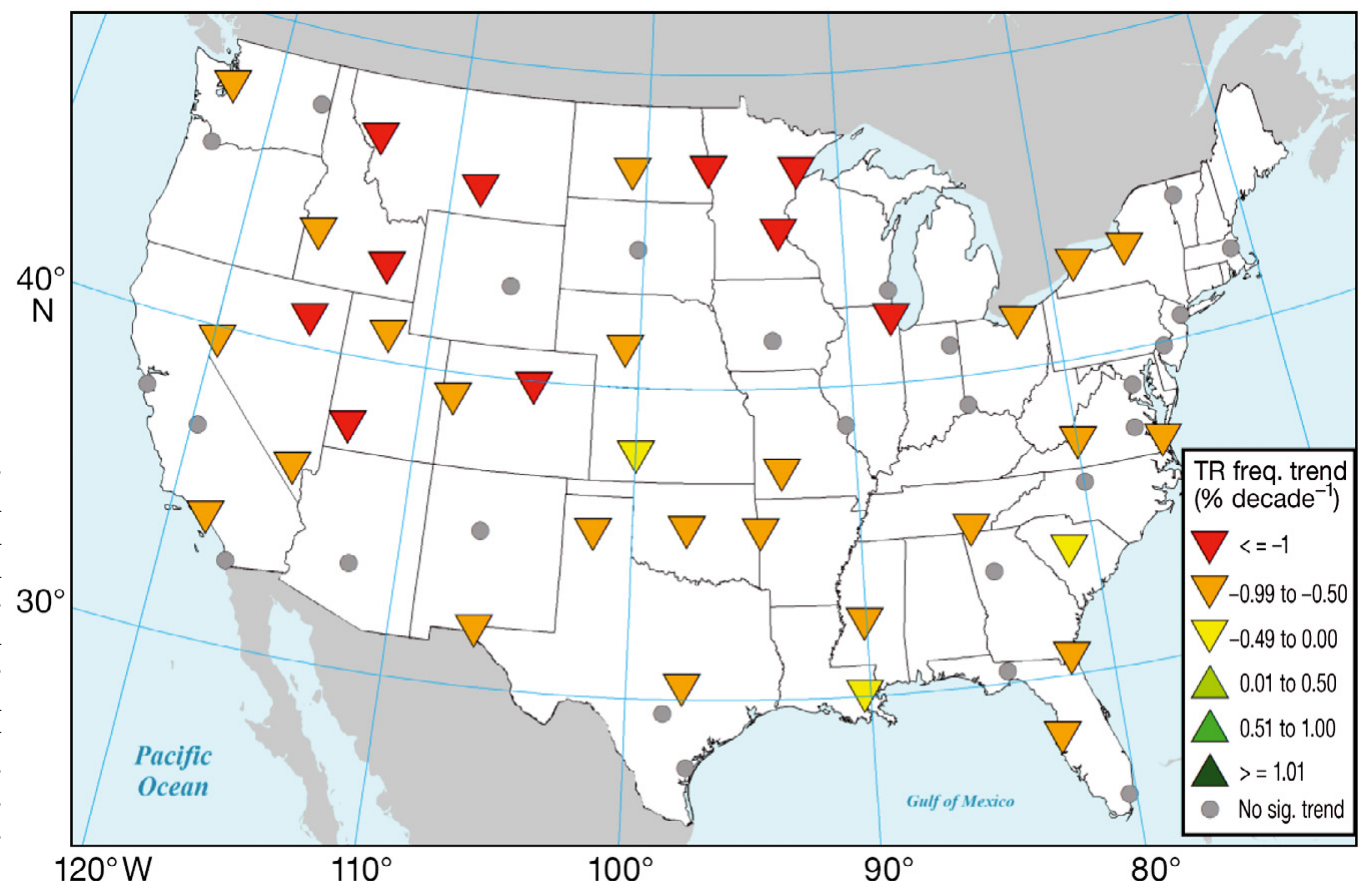


set of days that are mostly transitions. It is true that some transitions fall below the percentile threshold; however, setting the threshold at the 90th, rather than at the 80th percentile, ensures that most of the information used in subsequent analysis is more transition specific. Using the 90th percentile $R_{\mathrm{Td}}, R_{\mathrm{P}}$, and $R_{\mathrm{W}}$ as representative values for each winter provides a very different picture of cli-
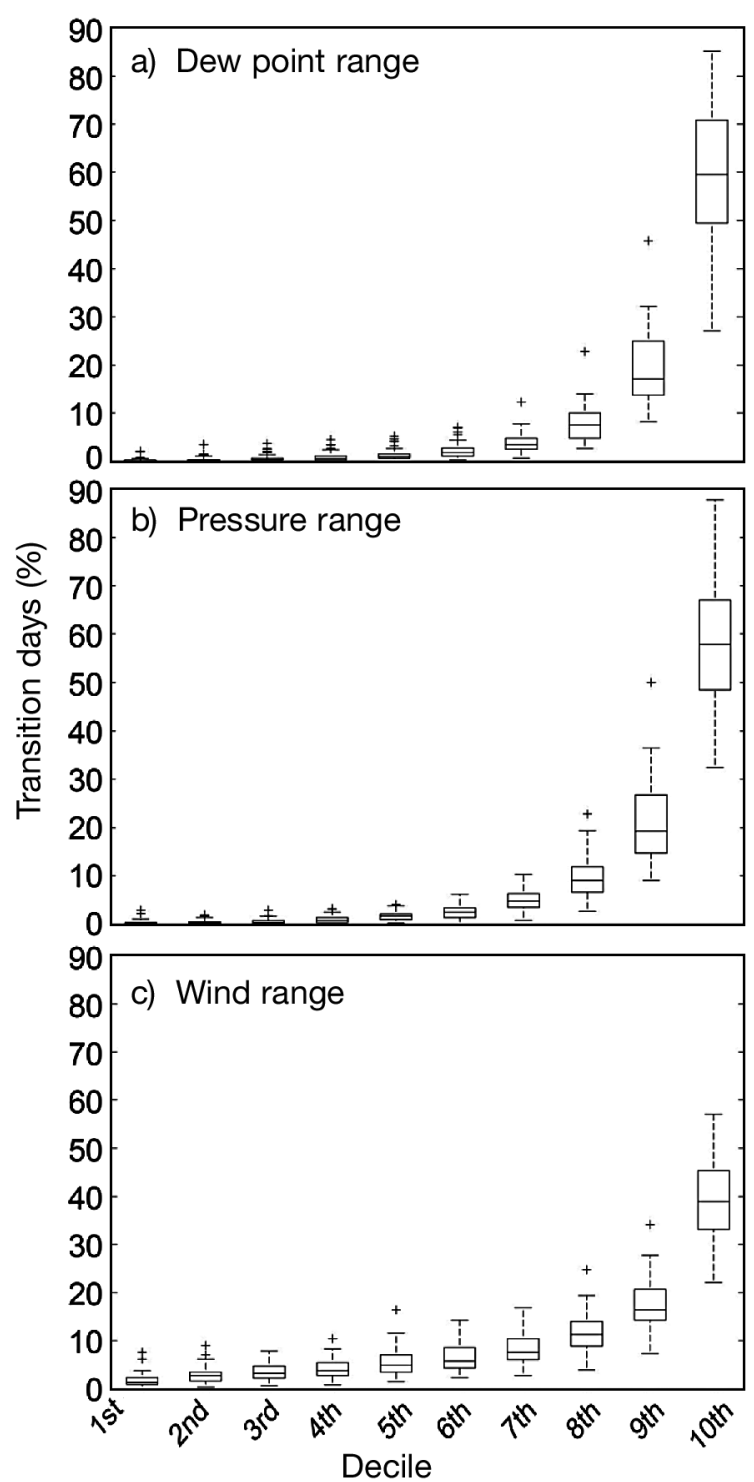

Fig. 5. Percentage of winter days within each decile of the transition indicator variables (a) dew point temperature, (b) sea-level pressure, and (c) wind that are transition days across the entire 63-station network. For example, in the case of dew point temperature, $<10 \%$ of the days with a dew point temperature range that falls in the sixth decile are transition days, regardless of station. When the dew point temperature range is in the tenth decile, however, it is accompanied by transition classification approximately $50 \%$ of the time. Box plots are drawn with the median marked as the center line. The 25th and 75th percentiles enclose each box, and the whiskers extend through 2.7 standard deviations. Data points falling outside of 2.7 standard deviations are marked individually matic variability than one might obtain from using the mean winter $R_{\mathrm{Td}}, R_{\mathrm{P}}$ and $R_{\mathrm{W}}$, or winter standard deviation of the 3 variables (Table 2). In the case of $R_{\mathrm{Td}}$, one might overestimate the spatial extent of the declining variability (as related to transition frequency) by using the seasonal mean, but underestimate the variability by using the seasonal standard deviation.

Given that the 90th percentile is a good benchmark of where transition days fall in the distribution of transition indicator variables, we compare trends in the 90th percentile $6 \mathrm{~h}$ changes to examine the effect of the SSC procedure's exclusion of overnight changes between 22:00 and 04:00 $\mathrm{h}$ the next day. In the case of $6 \mathrm{~h} R_{\mathrm{Td}}$, the $57 \mathrm{yr}$ trend between 22:00 and 04:00 $\mathrm{h}$ significantly differs from that between 04:00 and 10:00 h at only 4 stations, the 10:00-16:00 $\mathrm{h}$ trend is significantly different at 15 stations, and the 16:00-22:00 h trend is significantly different at 3 stations. However, in no case is the overnight trend more negative than those observed during the daytime periods. In other words, the 90th percentile dew point range between 22:00 and 04:00 $\mathrm{h}$ the next day is not decreasing at a rate greater than over any other $6 \mathrm{~h}$ period of the day. At only 1 station is there a difference between overnight and daytime trends, and the overnight trend is of lesser magnitude. No stations demonstrate significant differences between $6 \mathrm{~h}$ trends in $R_{\mathrm{W}}$. Overall, then, it is very unlikely that the decline in transition frequency is occurring simply because more transitions are being observed overnight, when the SSC might fail to correctly identify them.

The seasonal 90th percentile $R_{\mathrm{Td}}, R_{\mathrm{P}}$, and $R_{\mathrm{W}}$ collectively account for between 45 and $85 \%$ of the year-toyear variance in transition frequency, as demonstrated by stepwise multiple linear regression (Fig. 6). At most
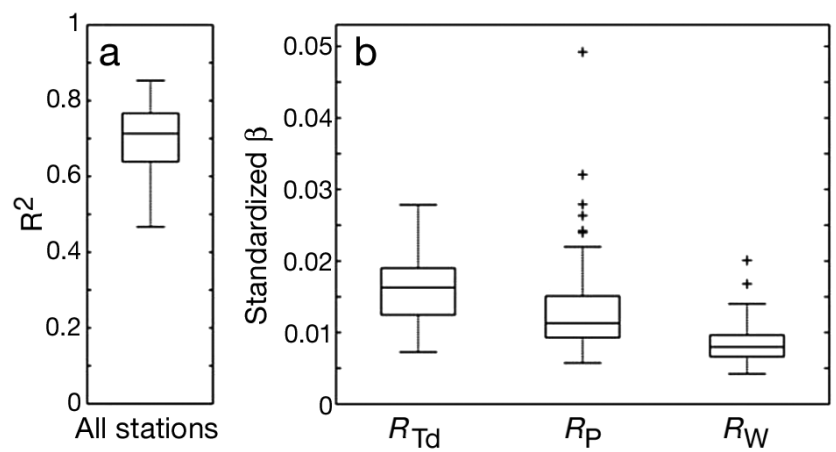

Fig. 6. (a) Box plot of adjusted $\mathrm{R}^{2}$ from stepwise multiple linear regression at 63 stations. Potential independent variables: winter 90th percentile dew point temperature range, 90th percentile sea-level pressure range, 90th percentile wind range, and the dependent variable is winter transition frequency. (b) Box plots of standardized regression coefficient $\beta$ for stepwise multiple linear regressions; wind range $\left(R_{\mathrm{W}}\right)$ included as a predictor at 41 stations, dew point temperature range $\left(R_{\mathrm{Td}}\right)$ and sea-level pressure range $\left(R_{\mathrm{P}}\right)$ included as predictors at all stations. Box plot markings, see Fig. 5 
Table 2. Comparison of the number of statistically significant trends in the winter mean, standard deviation, and 90th percentile of each of the 3 transition indicator variables across the 63-station network

\begin{tabular}{|lcccccccccc|}
\hline & \multicolumn{3}{c}{$\begin{array}{c}\text { Mean } \\
+\end{array}$} & No trend & $-\begin{array}{c}\text { SD } \\
+\end{array}$ & No trend & \multicolumn{3}{c|}{$\begin{array}{c}90 \text { percentile } \\
+\end{array}$} \\
\hline $\begin{array}{l}\text { Dew point } \\
\text { temperature range trend }\end{array}$ \\
$\begin{array}{l}\text { Sea-level } \\
\begin{array}{l}\text { pressure range } \\
\text { Wind range }\end{array}\end{array}$ & 38 & 0 & 25 & 20 & 1 & 42 & 29 & 1 & 33 \\
& 44 & 1 & 18 & 42 & 0 & 21 & 42 & 1 & 20 \\
\hline
\end{tabular}

stations, all 3 variables are used in the final regression model, and a statistically significant relationship is present with at least 2 of the variables at each of the 63 stations. The wind range is not included as a predictor at 22 stations. Overall, the stepwise regression demonstrates that the transition classification is sensitive to seasonal changes at the extreme high end of the range distributions for the transition indicator variables.

\subsection{Climatology of transition indicator variables and contribution to transition trends}

Across the 63 stations, dew point temperature range accounts for a larger portion of the variance in transition frequency than either sea-level pressure range or wind range (Fig. 6), although this is not necessarily the case at each individual station (Fig. 7). The relative sensitivity of the transition classification to each of the 3 variables differs from station to station (Fig. 7). The largest regression coefficients are found for dew point temperature range at several stations in the Rockies, and $R_{\mathrm{Td}}$ coefficients are mostly larger in the central states than in the East. The broad region of larger $R_{\mathrm{Td}}$ coefficients is coincident with the region of the maximum decline in transition frequencies (comparing Figs. 4 \& 7). In the case of $R_{\mathrm{P}}$, the regression coefficients are largest for the stations in California and Florida. In other words, the transition frequency in California and Florida is more dependent on the wintertime 90 th percentile $R_{\mathrm{P}}$ than at other stations. By comparing the maps of standardized multiple linear regression coefficients for $R_{\mathrm{Td}}$ and $R_{\mathrm{P}}$, one can observe that sea-level pressure has a much greater 'weight' in the regression in California and Florida. Finally, $R_{\mathrm{W}}$ is included as a predictor in the stepwise regression at 41 stations, although the regression coefficient for wind range is rarely greater than that of $R_{\mathrm{Td}}$ or $R_{\mathrm{P}}$. Given this insensitivity of the transition classification scheme to the wind range (as demonstrated by both the stepwise regression and 'threshold' analysis above), it is clear that the most important trends as related to transition frequency are found within $R_{\mathrm{Td}}$ and $R_{\mathrm{P}}$. Accordingly, those 2 variables are emphasized throughout the remainder of the discussion.

Decreases in the 90th percentile of $R_{\mathrm{Td}}$ are evident across the northern half of the country. The maximum
Fig. 7. Map of standardized multiple linear regression coefficients $(\beta)$ at each of 63 stations as described in Fig. 6. The independent variables are 90th percentile dew point temperature range (blue), 90th percentile sea-level pressure range (red), and 90th percentile wind range (yellow). The beta values for all significant predictors are plotted in pie charts at each station to indicate their relative magnitude

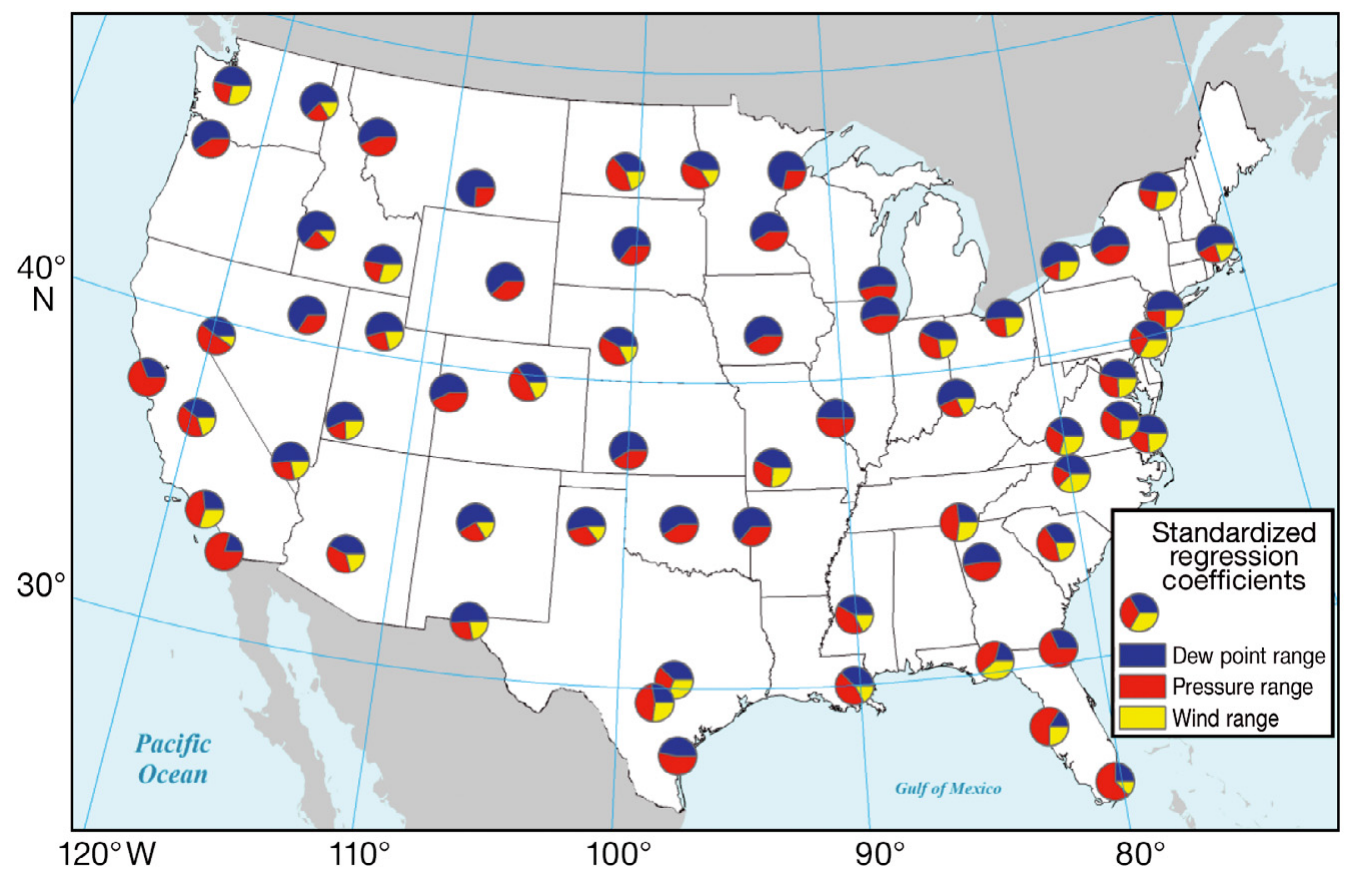


changes are observed in the upper Midwest and in the central Rockies (Fig. 8). We next examined if there were any trends in dew point temperatures at either end of the distribution of daily values to see if the decrease in range could be attributed to generally higher minima or lower maxima. Significant positive trends in the lowest percentiles of observed dew point temperature (rather than $R_{\mathrm{Td}}$ ) are present across much of the region where we also observed the greatest decline in dew point variability (Fig. 9). For the 10th percentile 04:00 h dew point temperature, for example, the increase approaches $1{ }^{\circ} \mathrm{C}$ decade $^{-1}$ in the upper Midwest. Significant positive trends are also present at a number of stations in the 10th percentile 10:00 and 22:00 $\mathrm{h}$ dew point temperatures (not shown). There are very few stations with significant increases in 10th percentile 16:00 $\mathrm{h}$ dew point temperatures, which is the time of day at which, on average, the highest of the 4-times daily dew point temperatures is observed at most stations. Connecting these results to those of $R_{\mathrm{Td}}$, the decline in dew point temperature variability over much of the region is in part related to an increase in the lowest dew point temperatures.

Large within-day changes in sea-level pressure (as measured by pressure range) are becoming less common over time across 3 proximate stations in the northern Rocky Mountains and at 3 other stations across the south (Fig. 10). No stations demonstrate increasing wintertime pressure variability. Compared with dew point temperature, a small number of stations exhibit trends in pressure variability. We note that at the stations in the northwest the minimum dew point temperatures were not increasing, suggesting that changes in pressure variability there are forcing the trends in dew point variability and transition frequency. At most stations, there are no trends in any component of the distribution of sealevel pressure, indicating that the trends in the change variables are not related to increasing minima, as was the case for dew point temperature at certain stations. Recalling that pressure range was included in all of the stepwise regression models above, the disparity of stations with a trend in sea-level pressure variability indicates that although sea-level pressure range is tied to transition frequency, it is the trend in dew point temperature range that is generally responsible for the decline in transition frequencies.

\subsection{Comparing transition frequency and circumpolar vortex position}

Statistically significant relationships between vortex position and transition frequency are evident at 52 of 63 stations (Fig. 11). A positive relationship indicates that transition frequencies are higher, with a mean vortex position in the higher latitudes, or in a contracted state. Similarly, an inverse relationship indicates that transition frequencies are greater when the vortex is farther south. In general, the variance explained by winter average vortex position is $30 \%$ or less; however, these models each have only 1 independent variable. The stations with the strongest relationship between vortex activity and transition frequency are located

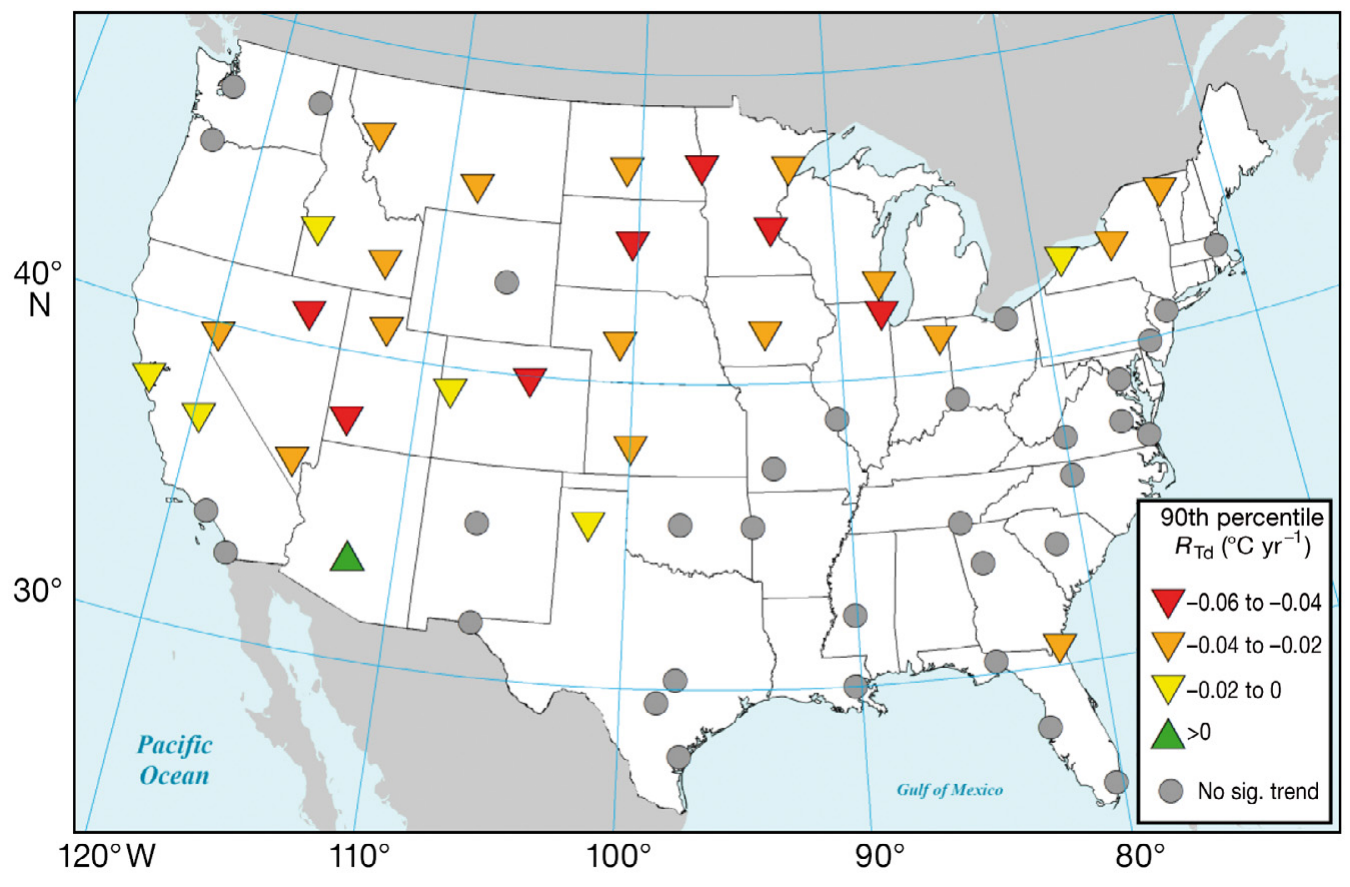

Fig. 8. Trends in the 90th percentile winter (DJF) dew point temperature range $\left(R_{\mathrm{Td}}\right)$ for the period December 1950 to February 2007 . The $R_{\mathrm{Td}}$ is defined as the absolute value of the difference between the maximum and minimum dew point temperatures observed at 04:00, 10:00, 16:00, and 22:00 h eastern standard time 
Fig. 9. Trends in the 10th percentile winter (DJF) 04:00 h Eastern Standard Time dew point temperature range $\left(R_{\mathrm{Td}}\right)$ for the period December 1950February 2007

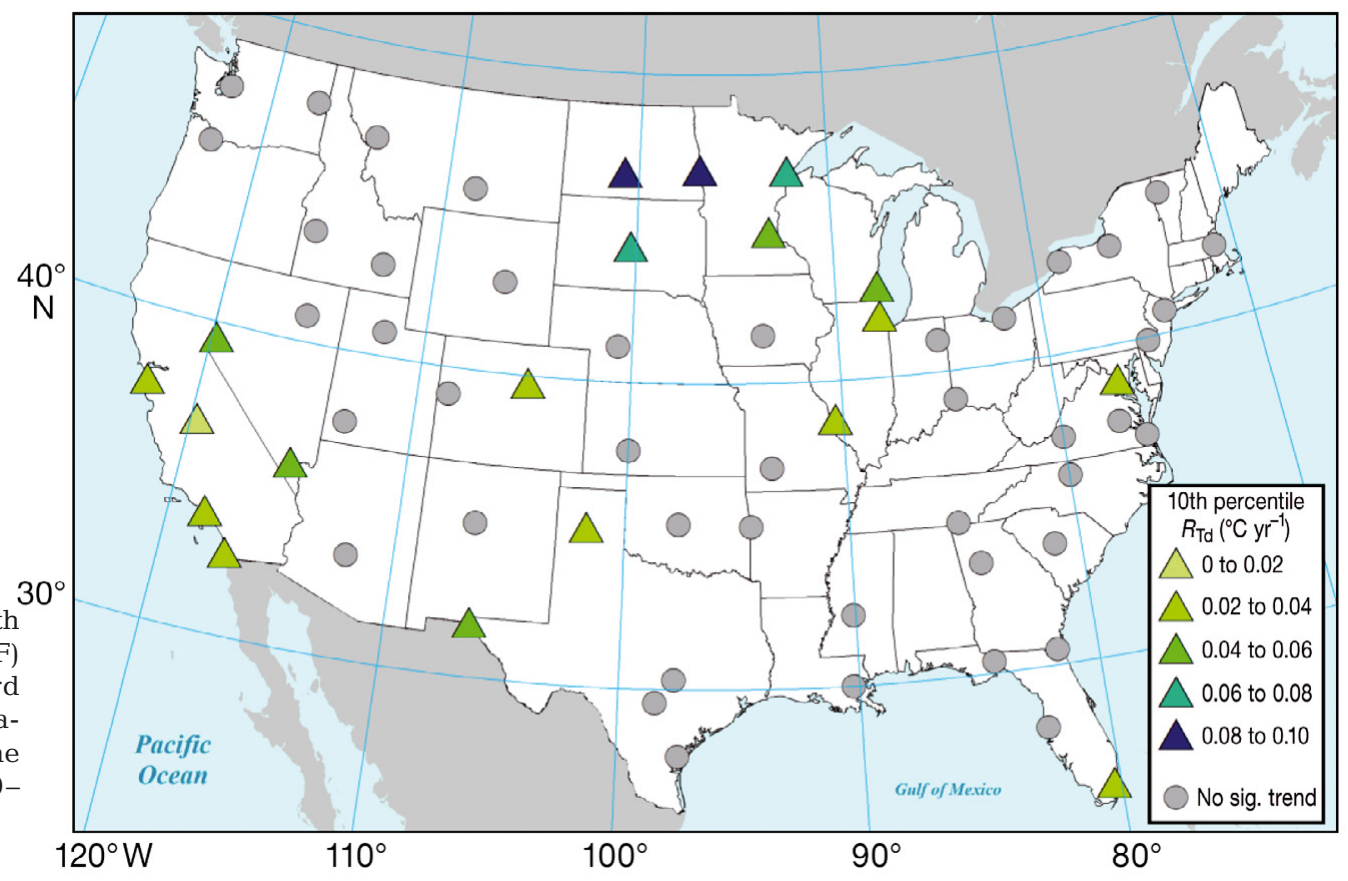

throughout the Rocky Mountain region and across the southeastern tier of the United States. For reference, the mean winter vortex position over North America is sinusoidal, with a northernmost extent along the Pacific coast at approximately $50^{\circ} \mathrm{N}$ and a southernmost extent at approximately $42^{\circ} \mathrm{N}$, near Lake Erie. There is considerable year-to-year variability in the average winter position, with a standard deviation $>4^{\circ}$ across the west, decreasing to roughly $2.5^{\circ}$ in the east. Since the 1970 s, the vortex has been significantly con- tracting across the United States, with the greatest trend in the western part of the continent (Frauenfeld \& Davis 2003).

We observe a high degree of spatial consistency in transition-vortex relationships. Vortex position over the eastern Pacific (125 to $140^{\circ} \mathrm{W}$ ) is positively correlated to transition frequencies across the Midwest and Northeast, as well as at Elko, Nevada, and Cedar City, Utah (grey circles in Fig. 11). There is an inverse relationship between vortex position over the United

Fig. 10. Same as Fig. 8, but for the 90th percentile winter (DJF) sea-level pressure

(SLP) range

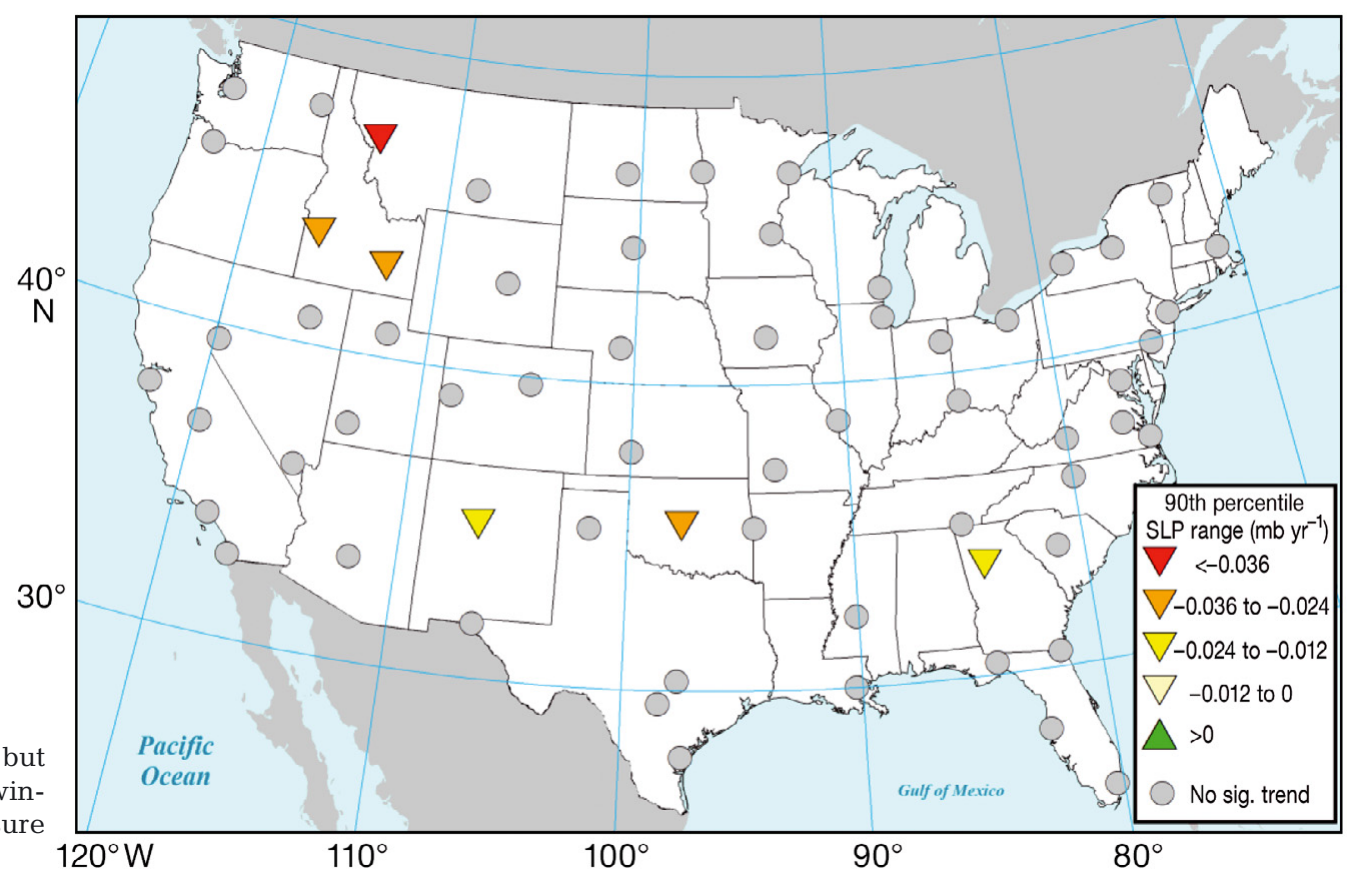




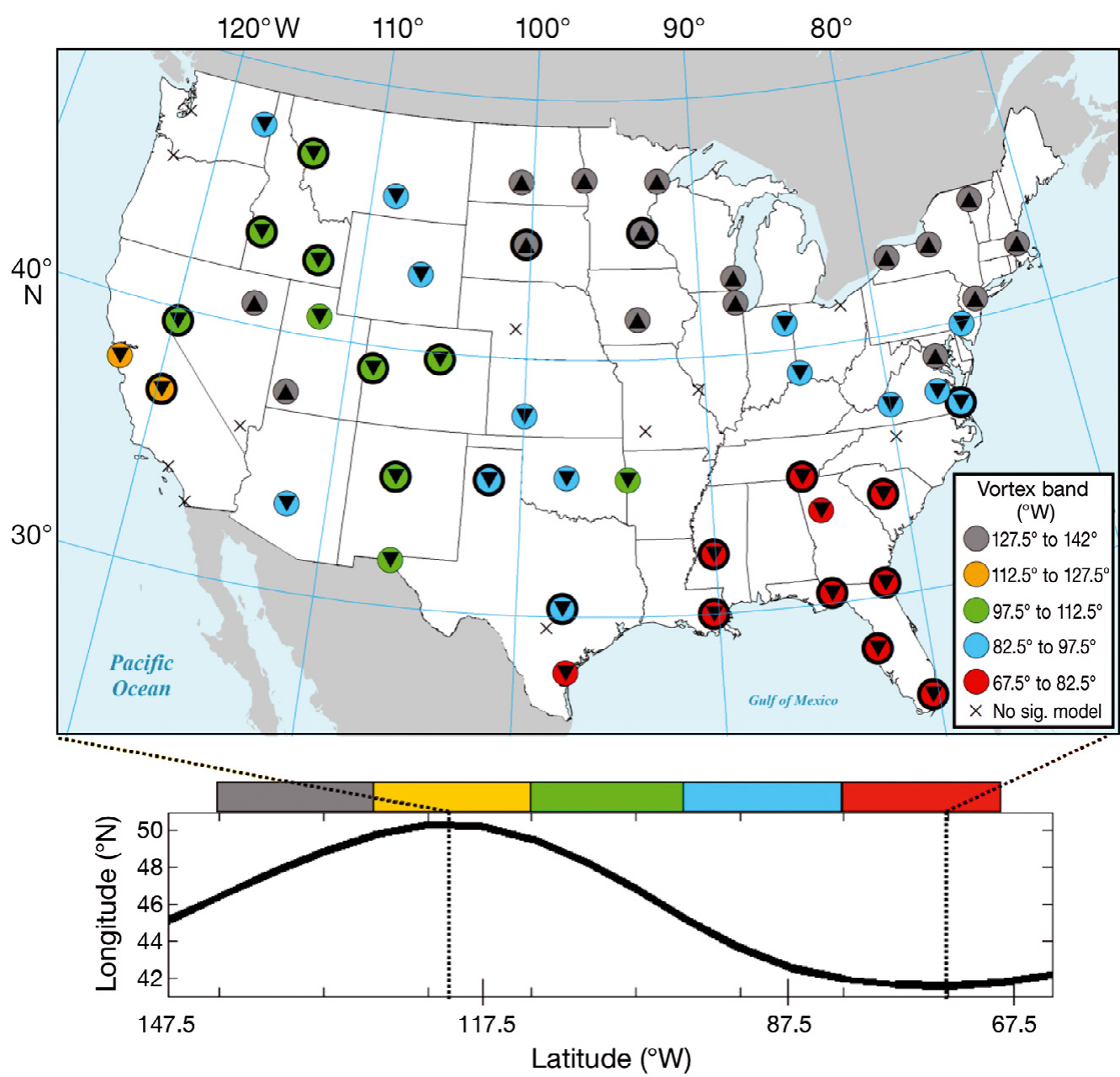

Fig. 11. Relationships between winter (DJF) spatial synoptic classification transition frequency and the latitudinal position of the Northern Hemisphere circumpolar vortex. A dot indicates a significant relationship between vortex position and transition frequency; the color corresponds to the $15^{\circ}$ longitude band with the highest correlation (average vortex shape shown in lower plot with matching colors). The triangle indicates the direction of the relationship between the vortex position and transition frequency-a positive relationship (north-pointing triangle) indicates higher transition frequencies when the vortex is more northerly. Black outlines around the colored dots identify stations where the residuals of the regression between vortex position and frequency demonstrate no significant trend. For example, the transition frequency at Denver, Colorado, is most correlated to vortex activity between 97.5 and $112.5^{\circ} \mathrm{W}$ (the green region), and the relationship is inverse, such that transition frequencies are higher when the vortex in that region is farther south

States and transition frequency at most other stations. In general, transition frequency is best-correlated with the vortex activity nearby or to the west, although a few exceptions are of note (e.g. Albuquerque, New Mexico, and Spokane, Washington). The possibility that transition frequency trends are dependent on the position of the vortex is supported by the fact that, at 21 stations, the residuals of the regression between vortex position and transition frequency demonstrate no temporal trend.

\section{DISCUSSION}

Our analysis, originally driven by the observed largescale decline in SSC transition frequencies, identifies a widespread decrease in dew point variability across much of the central and western continental United States. Decreases in the upper percentiles of $R_{\mathrm{Td}}$ may occur for 2 reasons: either the humidity before a transition event has changed relative to the moisture content following, or the number of boundaries between moist and dry air masses has decreased. We can attribute decreasing variability in the Midwest to the former, based on the significant dew point temperature increase in the low percentiles. Increasing moisture among the driest air masses is consistent with the results of Kalkstein et al. (1990), who identified increasing temperature and dew point temperature within western Arctic air masses using a synoptic classification approach similar to the SSC. A warming of the air masses with source regions in the Arctic is a possible outcome of increasing global temperatures associated with changing atmospheric trace gas concentrations (Kalkstein et al. 1990). The western Arctic is a common source region for anticyclones in the upper Midwest during the winter months (Klein 1957). The increasing moisture content of Arctic air masses may be important as far west as Grand Junction, Colorado, as a 'secondary track' of polar anticyclones follows a trajectory across Idaho, but we are not convinced that increasing moisture content among Arctic air masses is responsible for the changes observed at Reno and Las Vegas, Nevada, and nearby stations. If Arctic air masses were partially responsible for the increase at those locations, the signature 
should also be evident across stations in Idaho and Montana, where there are generally no trends in any percentile of dew point temperature.

Increasing moisture content of the driest Arctic air masses is a probable cause for decreasing transition frequency at stations across the upper Midwest. We also observe a link between increasing low dew point temperatures and decreasing transition frequencies at stations across Nevada, Utah, and Colorado, but a physical explanation based solely on the moisture properties of air masses remains elusive.

Decreases in pressure variability also are related to decreasing transition frequencies at a few stations where the minimum dew point temperatures are not increasing. However, as there are no significant trends in any components of the pressure distribution, our analyses do not suggest that the number of days with above-average pressure relative to days with below-average pressure has changed over the past several decades or that the intensity of high-pressure systems and low-pressure systems has changed. For the variability to decline, we contend that the rate of change between high and low values of pressure must have diminished over the past several decades, analogous to an increase in the wavelength of a periodic function with no change in amplitude. Applying a time series-based modeling approach may be one strategy to determine whether the persistence of air masses has increased over the half century.

The vortex relationships offer insight into the synoptic-scale patterns linked with the decline in transition frequency. The positive relationship between the vortex position over the Pacific and the transition frequency across the northern and eastern states indicates a linkage with the Aleutian Low, one of the centers of action of the Pacific-North American teleconnection pattern (e.g. Wallace \& Gutzler 1981). In phases when the low is weaker, the corresponding trough over the eastern United States also tends to be weaker. As a result, the trough in the eastern United States does not extend as far to the south, shifting the region of maximum cyclone activity into the Northeast. It is unclear why the vortex position over the Pacific, rather than the western United States, is more highly correlated with the transition frequency at Elko, Nevada, and Cedar City, Utah. Analysis of the configuration of the vortex during high- and low-transitionfrequency winters confirms that the shape of the Pacific trough is a better discriminator than the extent of the ridge over the West, but future research is necessary to determine the underlying reasons for this relationship. Another avenue for potential future research is the application of these methods to Canadian stations, to see if transition frequencies have increased as the vortex has shifted to a more northerly configuration.
With respect to the upper Midwest, however, the tendency for greater ridging in the west in recent years should increase the probability of Arctic air masses following a trajectory over the Dakotas and Minnesota. In the dew point data, then, we might expect to see greater variability caused by decreasing minimum temperatures because of more frequent extremely dry air masses. However, this contradicts our observation of decreasing variability and increasing minimum dew points. One theory we noted above was the increasing moisture content within Arctic air masses concurrent with increasing temperatures (Kalkstein et al. 1990). Accordingly, if air masses with an Arctic source region are being more commonly observed in the upper Midwest, low dew point temperatures would not decrease.

The strong inverse relationship between the magnitude of the ridge over the interior west and the transition frequency at nearby stations is unsurprising. With an enhanced ridge, the Pacific storm track is diverted to the north, reducing transition types related to the passage of low pressure centers. Additionally, cold fronts associated with polar air masses are less likely to be observed because the polar air masses are restricted to regions north of the ridge. Instead, subsidence is common (Leathers et al. 1991), and the greater amplitude of the wave pattern results in more persistent synoptic features.

With an enhanced ridge, moist Pacific and Gulf air is more easily advected into the region and northward into the Rockies, likely resulting in higher low percentile dew point temperatures. This effect would be most pronounced at the driest and southernmost locations, which may explain why stations such as Salt Lake City, Grand Junction, and Denver demonstrate a trend, whereas those in Idaho, with typically higher mean and minimum dew point temperatures, do not.

Decreasing pressure variability in the West is also consistent with increased ridging, as long waves in the atmosphere propagate more slowly than short waves. We expected to find decreased variability to be associated with more frequent high pressure days because of the increased ridge, but did not. Our current hypothesis is that with meridional flow, cyclogenesis is more likely with increased upper-level divergence. The low pressure systems that develop in the West are more likely to persist locally because of the displaced polar jet well to the north.

In contrast to the western half of the country, meridional flow is associated with elevated transition frequencies across the East. For the mid-Atlantic region, a more southerly vortex over the Midwest elevates transition frequencies. This may be caused by more common intrusions of polar air masses, as well as increased cyclogenesis downstream of the Rockies, with more meridional flow. It is unclear why there is a relation- 
ship between the vortex position over the Midwest and several stations upstream. Similarly to the midAtlantic, an enhanced trough over the east coast is associated with more transition activity in the Southeast.

Given the significant trends and relationships associated with circulation, how then are SSC transition days applicable in a more widely generalized meteorological paradigm? Many climatologists would agree that a more recognizable, related term for air-mass transition is 'frontal passage.' By definition, the transition category in the SSC is intended to identify those days in which 2 distinct air masses are resident over a station; this boundary is often identified as a frontal passage. However, it is not necessarily true that all frontal passages will be labeled as transition days in the SSC, nor must all transition days be frontal passages. Further, the transition demarcation provides no information about the type of change that is occurring. Is the transition from dry polar air to moist tropical (potentially a warm front), moist tropical to dry polar (potentially a cold front), or some other pattern? Hondula \& Davis (2010) develop a sub-classification scheme for transition days based on diurnal changes in dew point temperature and sea-level pressure. Across the same 63-station network used in the present study, most transition days (approximately 90\%) fall into the subtypes with oppositely signed changes (dew point temperature increase and sea-level pressure decrease and vice versa). These are the types of changes that would be expected in the classic Bjerknes cyclone model for warm fronts and cold fronts, respectively. The development of sub-types of transition days strongly suggests that many transition days are, in fact, frontal passages.

Much remains to be learned about the intricacies of the SSC with respect to transition days, frontal passages, and larger scale circulation. For example, an apparent discrepancy in our analysis can be seen by comparing the transition frequency trends and dew point temperature trends for 2 relatively proximate stations: Pierre, South Dakota (PIR), and Fargo, North Dakota (FAR). Although the 2 stations have significant negative trends in dew point temperature variability, and our regression analysis shows that transition frequency is mostly dependent on dew point variability at both, only 1 (FAR) has a significant trend in transition days.

Another outcome revealed in our analysis is the spatial variability evident in the relative contribution of the transition indicator variables to transition frequencies. We recognize that the transition frequency is ultimately determined by the underlying seed day characteristics of the SSC, local processes, and the synoptic-scale climate. For example, the transition frequency at several coastal locations is largely driven by the pressure range, which is rarely the key factor at most other stations. In terms of the seed day character- istics, most coastal locations have among the lowest expected values for pressure range on both transition days and air-mass days (averaging all 6 air-mass types together) during the winter months. If the seed day calibration underestimates the average pressure range at coastal locations, one would expect pressure range to be a greater contributing factor to transition reclassification. The pattern could be partially a function of the daily sea breeze/land breeze pattern, which leads to wind and potentially dew point temperature shifts on a daily basis. With a measureable wind shift and dew point temperature shift present on most days, it could be difficult for the SSC to distinguish those changes from frontal passages. The only factor remaining that could identify transition from air-mass days is sea-level pressure range. We suspect that both of these elements play a role in shaping the spatial patterns.

Unraveling the underlying cause of the decline in transition frequencies in the SSC requires analysis and understanding of both climatic variability and the intricacies of the SSC itself. Linking discrete daily weather types to continuously evolving synoptic-scale weather patterns is a challenging but useful endeavor. Research conducted using classification products like the SSC must be careful to accommodate the system's limitations. While we have attempted to keep the SSC's operational characteristics at the forefront of our research, this manuscript is not intended to serve as a complete validation of the SSC. Many interesting points related to the SSC have arisen from this work, which we hope will be considered in the future. One of our challenges was identifying the proper way to evaluate the transition indicator variables. We ultimately decided to measure the change in the 90th percentile for each variable on a year-to-year basis, because above the 90th percentile we began to see a sharp increase in the likelihood of transition classification (Fig. 5). Note, however, that even when the transition variables individually fall in the top decile, there are many days that are not transitions-roughly $40 \%$ of the days with a top-decile $R_{\mathrm{Td}}$ are not transitions, for example. This suggests that transition identification more frequently arises from multiple indicator variables falling in the top decile. This is presumably a strength of the SSC, in that there are a variety of synoptic patterns that can result in a substantial diurnal change in dew point temperature, pressure, or wind speed/direction that are not air-mass transitions. A cursory analysis revealed that, across the entire network, days with high values of $R_{\mathrm{Td}}$ that were not transitions tended to be more frequently associated with dry polar and dry tropical air-mass types than the background climatology. For days with high values of $R_{\mathrm{P}}$ we observed a greater likelihood of moist polar air, and, for $R_{\mathrm{W}}$, dry tropical, moist moderate, and moist tropical 
were most often seen. Future research directed at examining local-scale processes that impact air-mass and transition identification would greatly aid in determining the larger scale applicability of the SSC to climate analysis. We selected a network of stations with a certain spatial resolution and $6 \mathrm{~h}$ data for consistency with the SSC and synoptic-scale processes. However, additional research conducted with higher resolution spatial and/or temporal coverage could reinforce our findings, as well as provide additional insight into the objective numerical identification of frontal passages. We suspect that all users of the SSC and similar classification systems would welcome future research discussing how they might be improved or modified if hourly data were incorporated.

\section{CONCLUSIONS}

Decreasing SSC transition frequencies across much of the United States are associated with declining variability in dew point temperature and sea-level pressure. A portion of the variance can be explained by changes in the position of the Northern Hemisphere circumpolar vortex and related atmospheric circulation variability. Increasing meridionality in the vortex over western North America in recent years has led to a moderation of daily weather variability, such that in recent years fewer abrupt transitions are observed. We suggest that the persistence of air masses in this region has increased over the past few decades. In the upper Midwest, reduced transition frequencies are related to increasing low percentile dew point temperatures (i.e. moistening of the driest days). Given that dry air masses from high latitudes regularly follow a trajectory over the Midwest in the winter months, this finding is consistent with global warming projections of enhanced warming in the Arctic (e.g. Trenberth et al. 2007). Dew point temperature and pressure variability are not linked with decreases in transition frequency across much of the East.

This application of a synoptic-scale weather classification system to study decadal-scale trends in transition weather types provides a new perspective on the impacts of circulation changes on daily weather variability. For the upper Midwest, the difference between moist and dry air masses in the winter has moderated over the past half century. In the West, the number of transitional boundaries observed over a given time frame has decreased, and this trend is probably related to an increased residence time of the air masses. As synoptic-scale transition events are the major precipitation delivery mechanisms in winter over most of the United States, the changes we observe related to the decline in transition days may substantially impact the hydrologic cycle and surface systems.
Acknowledgements. B. Hayden and H. Shugart at The University of Virginia and Scott Sheridan at Kent State University helped advise and guide this research-their contributions are greatly appreciated. We are extremely grateful to 4 anonymous reviewers, who provided exceptionally thorough and beneficial critiques of our manuscript. D.M.H. is a National Science Foundation Graduate Research Fellow.

\section{LITERATURE CITED}

Burnett AW (1993) Size variations and long-wave circulation within the January Northern Hemisphere Circumpolar Vortex: 1946-1989. J Clim 6:1914-1920

Carnell RE, Senrio CA (1998) Changes in the mid-latitude variability due to increasing greenhouse gases and sulphate aerosols. Clim Dyn 14:369-383

> Changnon D, Noel JJ, Maze LH (1995) Determining cyclone frequencies using equal-area circles. Mon Weather Rev 123:2285-2294

> Davis RE, Benkovic SR (1994) Spatial and temporal variations of the January circumpolar vortex over the Northern Hemisphere. Int J Climatol 14:415-428

Efron B, Tibshirani R (1986) Bootstrap methods for standard errors, confidence intervals, and other measures of statistical accuracy. Stat Sci 1:54-75

Frauenfeld OW, Davis RE (2003) Northern Hemisphere circumpolar vortex trends and climate change implications. J Geophys Res D 108. doi:10.1029/2002JD002958

> Gong DY, Ho CH (2004) Inter-seasonal variability of wintertime temperature over east Asia. Int J Climatol 24:131-144

> Held IM (1993) Large-scale dynamics and global warming. Bull Am Meteorol Soc 74:228-241

Hondula DM, Davis RE (2010) Climatology of winter transition days for the contiguous USA, 1951-2007. Theor Appl Climatol 103:27-37

Kalkstein LS, Dunne PC, Vose RS (1990) Detection of climatic change in the western North American Arctic using a synoptic climatological approach. J Clim 3:1153-1167

Kalkstein LS, Sheridan SC, Graybeal DY (1998) A determination of character and frequency changes in air masses using a spatial synoptic classification. Int J Climatol 18: 1223-1236

Karl TR, Knight RW (1998) Secular trends of precipitation amount, frequency, and intensity in the United States. Bull Am Meteorol Soc 79:231-241

Karl TR, Knight WR, Plummer N (1995) Trends in highfrequency climate variability in the twentieth century. Nature 377:217-220

Klein WH (1957) Principal tracks and mean frequencies of cyclones and anticyclones in the Northern Hemisphere. Research Paper 40, US Weather Bureau, Washington, DC

Knight DB, Davis RE, Sheridan SC, Hondula DM and others (2008) Increasing frequencies of warm and humid air masses over the conterminous United States from 1948 to 2005. Geophys Res Lett 35:L10702. doi:10.1029/2008GL 033697

Lambert SJ (1995) The effect of enhanced greenhouse warming on winter cyclone frequencies and strength. J Clim 8: 1447-1452

> Leathers DJ, Yarnal B, Palecki MA (1991) The Pacific/North American teleconnection pattern and United States climate. I. Regional temperature and precipitation associations. J Clim 4:517-528

McCabe GJ, Clark MP, Serreze MC (2001) Trends in Northern Hemisphere surface cyclone frequency and intensity. J Clim 14:2763-2768 
Meehl GA, Tebaldi C (2004) More intense, more frequent, and longer lasting heat waves in the 21st century. Science 305:994-997

Paciorek CJ, Risbey JS, Ventura V, Rosen RD (2002) Multiple indices of Northern Hemisphere cyclone activity, winters 1949-99. J Clim 15:1573-1590

Rind D, Goldberg R, Hansen C, Rosenzweig C, Ruedy R (1990) Potential evapotranspiration and the likelihood of future drought. J Geophys Res D 95:9983-10004

Rohli RV, Wrona KM, McHugh MJ (2005) January Northern Hemisphere circumpolar vortex variability and its relationship with hemispheric temperature and regional teleconnections. Int J Climatol 25:1421-1436

Sheridan SC (2002) The redevelopment of a weather-type classification scheme for North America. Int J Climatol 22: $51-68$

Editorial responsibility: Peter Gleckler,

Livermore, California, USA
Strong C, Davis RE (2007) Winter jet stream trends over the Northern Hemisphere. Q J R Meteorol Soc 133:2109-2115 Trenberth KE, Jones PD, Ambenje P, Bojariu R and others (2007) Observations: surface and atmospheric climate change. In: Solomon S, Qin D, Manning M, Chen Z, Marquis M, Avery KB, Tignor M, Miller HL (eds) Climate change 2007: the physical science basis. Contribution of Working Group I to the 4th assessment report of the Intergovernmental Panel on Climate Change. Cambridge University Press, Cambridge, p 235-336

- Wallace JM, Gutzler DS (1981) Teleconnections in the geopotential height field during the Northern Hemisphere winter. Mon Weather Rev 109:784-812

Yin JH (2005) A consistent poleward shift of the storm tracks in simulations of 21st century climate. Geophys Res Lett 32:L18701. doi:10.1029/2005GL023684

Submitted: July 30, 2009; Accepted: November 1, 2010

Proofs received from author(s): February 3, 2011 